strokes. These precepts and a few 'minor ones have been easily followed in all cases. I inclose a few lines copied from your interesting journal by a youth who does not understand English : he would have done this work with more care had he known that I wanted merely a sample. At all events it is most easy to read.

Straight letters without hair lines give the reader a comfortable facility which is a far greater compliment to a correspondent than the "dear Sir" imported from England to France during the last fifty years. We suppose that slant writing has been invented on your side of the Channel, and we call it therefore écriture anglaise. However, experience seems to show that it is more easily deformed than a straight one, and that it degenerates often into an illegible scrawl, causing much loss of time, or even, what is worse, a tiresome amount of perplexity and worry. We are told that the schoolmaster is abroad, but I am afraid that he leads our children on a false trail far away from the main aim of writing, which is legibility. Is the invention of typewriters the antidote or the outcome of illegible slants? Some of your philosophers may answer this question while giving a wholesome lesson to the schoolmaster.

A. D'ABBADIE (de l'Institut).

Abbadia, Hendaye, France, August 16.

\section{Cordylophora lacustris.}

IN NATURE for June 4 (p. 106) Mr. John Bidgood recorded the presence of this Hydrozoon in vast numbers on submerged roots and stems in the Ant, Bure, and Thurne. Till then its only known Norfolk locality was that given in Allman-" an agricultural drain near Lynn Regis." This summer innumerabie colonies were to be seen on weed floating on the surface on both sides of the Thurne from Ludham Bridge right up to Hickling Broad. A buatman told me he had seen "them insecs" every summer for many years past. Mr. Edward Corder, the Secretary of the Norwich Natural History Society, took some early in June, and some, which he was good enough to send me, is still living in a 4-ounce bottle. All the authorities state that Cordylophora is a "light-shunning animal," and the localities hitherto recorded certainly warranted such a conclusion. But the colonies taken from the surface of the water by Mr. Corder, and those I took some time later, were stronger and cleaner than those obtained from below the surface. I distributed some of the gathering which I brought back to London, and learn that it is all doing well in ordinary aquaria. Some that I sent to $\mathrm{Mr}$. Bolton for distribution unfortunately died in transit. One large colony, some eight inches long, on the stem of a Potamogeton, was kept in the shade for a fortnight ; the tubes became flaccid, and the hydranths pendent, but they revived within twenty-four hours when exposed on the ledge of a window with a western aspect. This seems to point to a change of habit. All the colonies were doubtless founded below the surface of the water, and the weeds, when cut to clear the fairway for wherries, were floated up towards Hickling Broad by the tide. But if reproduction takes place-as it certainly does-under these conditions, is it not probable that we shall have a race tolerant of direct light, if not as sensitive thereto as Hydra vulgaris?

5 Osborne Road, Stroud Green, N., September 3.

\section{Absolute and Gravitation Systems.}

THE present condition of things is such that students of engineering need familiarity with, and ability to use, both systems o measuring force and related quantities. It seems necessary, therefore, that the transition from one system to the other should be kept clear of complications, and be presented as the simple matter which it really is. But in two text-books which have come to my notice, each offering points of excellence, and both evidently written by competent hands, a change in the unit of mass occurs in passing from the absolute to the gravitation system. The unit-mass is defined as the mass in which unit-acceleration is produced by unit force, which, of course, gives about 32 pounds as the mass-unit for the British gravitation system.

There is, in my opinion, much that is undesirable about this method of statement; the new mass-unit appears quite artificially in this one only of the many uses of the conception of mass, for the purpose, I suppose, of making it possible to put in

NO. I I 4 I, VOL. 44$]$ generally applicable form such statements as: "Force is measured by change per second in momentum." My particular objection to it, however is that it locates the point of divergence among the fundamental units instead of among those derived from them. Does it not seem preferable to begin with units of mass, length, and time; to construct derived units, and to make common use of these as far as possible, postponing the differentiation of the two systems till the moment when it actually occurs? Surely it has been pointed out often, since the days of early exposition of these matters by Maxwell, Tait, and others, that the force-unit is the first cardinal point of difference, and that the absolute system simplifies here, while the gravitation system adopts another convention, which may be called arbitrary as opposed to the simpler one fixed upon by its rival.

In the hope of hastening the day of agreement in presenting the connection of ideas which underlie so much of modern physics and its applications, I have thought it permissible to state in summary, and for British units, the scheme used in my own teaching of mechanics. The claim is not advanced that the numerical work becomes different; indeed, the appended table is equally valid whichever basis be chosen; but there does seem to be a gain in logical clearness, as well as in what we may call historical accuracy.

Absolute System. - Fundamental units : foot, pound, second. Units of force, work, impulse derived in the usual way, so as to make proportional factors unity.

Gravitation System.-Fundamental units as before. Unit of force, the weight of one pound under circumstances specified to the required degree for scientific definiteness (locality, vacuum). Units of work and impulse connected with the force-unit, so as to make proportional factors unity.

The table shows the matter at a glance. $g_{1}$ is the value of $g$ for the standard circumstances, and is to be regarded as a divisor in each case affecting the product of the other factors. The other symbols explain themselves.

$$
\begin{aligned}
\text { Absolute. } & \\
\mathrm{P} & =m p, \\
\text { (work) } \int \mathrm{P} d s & =\text { (change in) } \frac{m v^{2}}{2}, \\
\text { (impulse) } \int \mathrm{P} d t & =\text { (change in) } m v . \\
\text { Gravitation. } & \\
\mathrm{P} & =\frac{m p}{g_{1}}, \\
\text { (work) } \int \mathrm{P} d s & =(\text { change in }) \frac{m v^{2}}{2 g_{1}}, \\
\text { (impulse) } \int \mathrm{P} d t & =\text { (change in) } \frac{m v}{g_{1}} .
\end{aligned}
$$

The choice of force-unit here affects what is logically subsequent to it, as it must; but leaves unaffected what is logically antecedent, as it ought.

So small a change as that of regarding $g_{1}$ as a divisor of $m$ alone changes the basis of presentation ; but there is an important difference of thought involved.

University of California.

\section{Eucalyptus as a Disinfectant.}

IN a paragraph on the use of Eucalyptus branches for disinfection, as recommended by Baron von Mueller, you have unintentionally stated that to be the manner in which $\mathrm{I}$ have used Eucalyptus.

For the last two years I have used “ Tucker's Eucalyptus Dis. infectant" (a solution of antiseptics in the essential oil) in all cases of scarlet fever and diphtheria, and have not had one case of infection. In the former disease I have not used any isola tion, and in most cases have not excluded the other children of the family from the sick-room. None of the cases, except two or three that were severe, were kept to their bed-room more than ten days ; the isolation of six or eight weeks being unnecessary, as the cuticle is perfectly disinfected. This is accomplished by rubbing the disinfectant over the whole body twice and then once a day for ten days.

Baron von Mueller, in a letter I received from him, quite approves of my method of disinfecting by inunction. I read a 